\title{
Correlação entre produtividade do arroz no sistema semeadura direta e atributos do solo ${ }^{1}$
}

Sinnara G. de Godoy ${ }^{2}$, Luís F. Stone ${ }^{3}$, Enderson P. de B. Ferreira ${ }^{4}$, Tarcísio Cobucci $^{5}$ \& Mábio C. Lacerda ${ }^{6}$

\section{Palavras-chave: Oryza sativa L. atributos físicos atributos químicos atributos biológicos qualidade do solo}

\begin{abstract}
R E S U M O
Objetivou-se, com este trabalho, identificar um conjunto de atributos do solo correlacionados com a produtividade do arroz de terras altas visando estabelecer as condições de solo mais adequadas ao cultivo deste cereal em semeadura direta. Em Santo Antônio de Goiás, GO, em áreas cultivadas, respectivamente por um, dois e três anos com arroz em semeadura direta, foi determinada a produtividade do arroz e retiradas amostras de solo na camada de 0,00-0,10 m de um Latossolo Vermelho ácrico, para determinação de atributos físicos, químicos e biológicos. A produtividade apresentou correlação positiva com os teores de nitrogênio total, cobre, ferro, manganês, carbono e nitrogênio da biomassa microbiana (NBM), atividade enzimática total e da fosfatase ácida, quociente microbiano e relação NBM:N total e negativa com a microporosidade e quociente metabólico. Pela análise de regressão linear múltipla os atributos do solo que melhor explicaram, de maneira conjunta, a produtividade, foram os teores de cobre, ferro e nitrogênio da biomassa microbiana e a atividade da fosfatase ácida.
\end{abstract}

\section{Key words:}

Oryza sativa L. physical attributes chemical attributes biological attributes soil quality

\section{Correlation between upland rice yield under no-tillage system and soil attributes}

\begin{abstract}
A B S T R A C T
This study aimed to identify a set of soil attributes correlated to upland rice yield in order to establish the most adequate soil conditions to cultivate this cereal under no-tillage system. In Santo Antônio de Goiás, GO, in areas cropped with upland rice under no-tillage system for one, two or three years, respectively, rice yield was determined and soil samples were collected from soil layer of 0-0.10 m of an Acric Red Latosol (Oxisol) to determine physical, chemical and biological attributes of soil. Grain yield showed positive linear correlation with total nitrogen, copper, iron, manganese, microbial biomass carbon and nitrogen $(\mathrm{MBN})$ contents, total enzymatic and acid phosphatase activities, microbial quotient and MBN:total $\mathrm{N}$ relationship, and negative with the microporosity and metabolic quotient. Based on multiple regression analysis, copper, iron and MBN contents and acid phosphatase activity were the soil attributes that together better explained rice yield.
\end{abstract}

Protocolo 012.14 - 14/01/2014 • Aprovado em 12/09/2014 • Publicado em 01/02/2015

${ }^{1}$ Parte da Tese de Doutorado do primeiro autor, apresentada na Universidade Federal de Goiás

${ }^{2}$ Pós-Graduação em Agronomia/UFG. Goiânia, GO. E-mail: sinnaragodoy@gmail.com

${ }^{3}$ Embrapa Arroz e Feijão. Santo Antônio de Goiás, GO. E-mail: luis.stone@embrapa.br (Autor correspondente) - Bolsista PQ do CNPq

${ }^{4}$ Embrapa Arroz e Feijão. Santo Antônio de Goiás, GO. E-mail: enderson.ferreira@embrapa.br

${ }^{5}$ Embrapa Arroz e Feijão. Santo Antônio de Goiás, GO. E-mail: tarcisio.cobucci@embrapa.br

${ }^{6}$ Embrapa Arroz e Feijão. Santo Antônio de Goiás, GO. E-mail: mabio.lacerda@embrapa.br 


\section{INTRODUÇÃo}

Historicamente, o cultivo do arroz (Oryza sativa L.) de terras altas assumiu papel importante como cultura pioneira no processo de ocupação agrícola do Cerrado, iniciado na década de 1960. Com a progressiva redução das áreas de abertura, em meados da década de 1980, a área cultivada com arroz sob o sistema de sequeiro foi sendo gradativamente reduzida. Ao longo dos anos a área semeada com arroz de terras altas decresceu em $61 \%$, passando de 3,1 milhões para 1,2 milhão de hectares de 1990 a 2011 (EMBRAPA, 2014). O aumento verificado na produtividade, que passou de 949 para 1982 $\mathrm{kg} \mathrm{ha}^{-1}$, não foi suficiente para compensar a perda na produção em virtude da diminuição da área cultivada; apesar disto, o Brasil é um dos poucos países do mundo onde o arroz de terras altas desempenha papel de fundamental importância no abastecimento interno desse grão para a população, atuando como regulador de preços.

Mesmo com os avanços tecnológicos alcançados nos últimos anos, em muitas regiões o arroz de terras altas continua sendo usado principalmente para o cultivo inicial de áreas de Cerrado e posterior substituição por soja ou pastagens; contudo, o sistema mais promissor para esta cultura seria sua inserção como mais uma opção de rotação com a soja em semeadura direta. $\mathrm{O}$ cultivo deste cereal em semeadura direta, entretanto, tem sido de alto risco e, atualmente, as pesquisas são ainda incipientes. Alguns autores obtiveram menores produtividades neste sistema quando comparado com o preparo convencional do solo (Santos et al., 2007), atribuído ao maior grau de compactação do solo. Entretanto, já foi demonstrado potencial produtivo do sistema convencional igual ao da semeadura direta (Reis et al., 2007).

Informações sobre indicadores de qualidade do solo podem contribuir para determinar, com maior precisão, as condições de solo adequadas para o cultivo de arroz em semeadura direta. Os atributos físicos do solo apresentam vantagens relacionadas ao baixo custo, metodologias simples e rápidas e relação direta com os atributos químicos e biológicos do solo (Mendes et al., 2006). Os atributos biológicos, por sua vez, têm sido considerados preditores precoces de mudanças na qualidade do solo por serem mais sensíveis que os atributos químicos e físicos (Lopes et al., 2013).

Devido à inter-relação entre os atributos do solo torna-se difícil, contudo, estabelecer relações de causa e efeito entre atributos isolados e produtividade do arroz de terras altas. Desta maneira buscou-se, com este trabalho, identificar um conjunto de atributos do solo correlacionados com a produtividade do arroz visando estabelecer as condições de solo mais adequadas ao cultivo deste cereal, no sistema de semeadura direta.

\section{Material e Métodos}

O trabalho foi conduzido na Fazenda Capivara, da Embrapa Arroz e Feijão, situada no município de Santo Antônio de Goiás, GO, cujas coordenadas geográficas são: latitude $16^{\circ} 28^{\prime}$ $00^{\prime \prime} \mathrm{S}$, longitude $49^{\circ} 17^{\prime} 00^{\prime}$ 'W e altitude de $823 \mathrm{~m}$. O clima, conforme classificação de Köppen, é Aw, tropical de savana, megatérmico. O regime pluvial é bem definido, com período chuvoso de outubro a abril e seco de maio a setembro, com precipitação média anual de $1485 \mathrm{~mm}$ (Silva et al., 2010). O solo das áreas estudadas é um Latossolo Vermelho ácrico, de textura argilosa, com teores médios de $307 \mathrm{~g} \mathrm{~kg}^{-1}$ de areia, 153 $\mathrm{g} \mathrm{kg}^{-1}$ de silte e $540 \mathrm{~g} \mathrm{~kg}^{-1}$ de argila, na camada de 0,00-0,10 m.

$\mathrm{A}$ análise química inicial apresentou valores médios semelhantes nesta camada para as áreas estudadas, com $\mathrm{pH}$ $\left(\mathrm{H}_{2} \mathrm{O}\right)=5,4 ; \mathrm{Ca}^{2+}=16,0 \mathrm{mmol}_{\mathrm{c}} \mathrm{dm}^{-3} ; \mathrm{Mg}^{2+}=5,3 \mathrm{mmol}_{\mathrm{c}} \mathrm{dm}^{-3}$; $\mathrm{Al}^{3+}=2,3 \mathrm{mmol}_{\mathrm{c}} \mathrm{dm}^{-3} ; \mathrm{H}^{+}+\mathrm{Al}^{3+}=41,0 \mathrm{mmol}_{\mathrm{c}} \mathrm{dm}^{-3} ; \mathrm{P}=22,4$ $\mathrm{mg} \mathrm{dm}{ }^{-3} ; \mathrm{K}^{+}=92,5 \mathrm{mg} \mathrm{dm}^{-3} ; \mathrm{Cu}^{2+}=1,6 \mathrm{mg} \mathrm{dm}^{-3} ; \mathrm{Zn}^{2+}=5,1 \mathrm{mg}$ $\mathrm{dm}^{-3} ; \mathrm{Fe}^{3+}=27,7 \mathrm{mg} \mathrm{dm}{ }^{-3} ; \mathrm{Mn}^{2+}=12,9 \mathrm{mg} \mathrm{dm}^{-3} ;$ capacidade de troca de cátions a pH $7(\mathrm{CTC})=64,7 \mathrm{mmol}_{\mathrm{c}} \mathrm{dm}^{-3}$ e saturação por bases $(\mathrm{V})=36,6 \%$. A vegetação original das áreas era do tipo Cerradão.

As áreas estudadas foram cultivadas, respectivamente, por um, dois e três anos com arroz em semeadura direta. Na área de primeiro ano o arroz foi semeado sobre a palhada da soja cultivada no ano anterior, após dois anos de pastagem de Brachiaria brizantha. A linhagem Primavera CL 431 foi semeada em novembro de 2010, no espaçamento de 0,45 $\mathrm{m}$, após 20 dias da dessecação da palhada com glifosato na dose de $4 \mathrm{~L} \mathrm{ha}^{-1}$. Nas áreas de segundo e terceiro anos de cultivo sucessivo, o arroz foi semeado sobre as palhadas de milho, milheto, Brachiaria ruzizienses, Brachiaria brizantha e Panicum maximum, semeados em abril do mesmo ano. Antes do primeiro cultivo de arroz essas áreas vinham sendo cultivadas há seis anos, em semeadura direta, com a rotação milho e soja no verão, com pousio no inverno. A linhagem, o espaçamento a data e o manejo da palhada foram os mesmos da área de primeiro ano.

Em todas as áreas a adubação de base foi feita com $400 \mathrm{~kg}$ $\mathrm{ha}^{-1}$ da fórmula 5-30-15 + 1\% Zn e 13 dias após a semeadura foram aplicados, em cobertura, $45 \mathrm{~kg} \mathrm{ha}^{-1}$ de $\mathrm{N}$, na forma de ureia. Aos 12 dias da semeadura foi aplicado o herbicida imazapyr + imazapic (100 $\mathrm{g} \mathrm{ha}^{-1}$ do p.c.) e aos 27 dias foram aplicados o fungicida cresoxim-metil + epoxiconazol $\left(0,7 \mathrm{~L} \mathrm{ha}^{-1}\right.$ do p.c.) e o fertilizante foliar organomineral Aminosan (1 L $\mathrm{ha}^{-1}$ ), cuja composição é de $112,5 \mathrm{~g} \mathrm{~L}^{-1}$ de $\mathrm{N} ; 25,0 \mathrm{~g} \mathrm{~L}^{-1}$ de $\mathrm{P}_{2} \mathrm{O}_{5}$; 2,5 $\mathrm{g} \mathrm{L}^{-1}$ de $\mathrm{K}_{2} \mathrm{O}$ e 131,2 $\mathrm{g} \mathrm{L}^{-1}$ de carbono orgânico.

Em fevereiro de 2011 foi realizada a colheita do arroz em uma área de 0,9 $\mathrm{m}^{2}$, composta de duas linhas de 1,0 m, para determinação da produtividade. Na mesma ocasião também foi realizada amostragem de solo para análises física, química e biológica na camada de 0,00-0,10 m. Em razão das dimensões de cada área $(0,25$ ha para a área de primeiro ano e 0,15 ha para as de segundo e terceiro anos), foram amostrados 18 pontos na área de primeiro ano, 11 na de segundo ano e 10 na de terceiro ano, com quatro repetições. Nas duas últimas áreas todas as palhadas antecedentes foram consideradas na amostragem. Procurou-se amostrar locais dentro das áreas em que a produtividade esperada era a mais divergente possível na tentativa de se obter maior variabilidade, tanto da produtividade como dos atributos do solo.

Os atributos físicos avaliados foram densidade do solo, determinada pelo método do anel volumétrico, porosidade total, pela relação entre a densidade do solo e a densidade de partículas determinada pelo método do balão volumétrico, microporosidade, considerada igual à quantidade de água retida pelo solo na tensão de $6 \mathrm{kPa}$, macroporosidade, pela diferença 
entre a porosidade total e a microporosidade, diâmetro médio ponderado dos agregados (DMP), determinado via úmida, e porcentagem de agregados com diâmetro maior que $2 \mathrm{~mm}$, sendo as análises realizadas segundo EMBRAPA (1997). Foram determinados, ainda, o índice S, conforme Dexter (2004), e a resistência do solo à penetração $(\mathrm{RP})$, com penetrômetro de impacto. As amostragens foram feitas um dia após uma chuva, com a umidade do solo próxima da capacidade de campo.

Os atributos químicos avaliados foram o $\mathrm{pH}$ do solo e os teores de $\mathrm{C}, \mathrm{N}, \mathrm{Ca}^{2+}, \mathrm{Mg}^{2+}, \mathrm{Al}^{3+}, \mathrm{H}^{+}+\mathrm{Al}^{3+}, \mathrm{P}, \mathrm{K}^{+}, \mathrm{Cu}^{2+}, \mathrm{Zn}^{2+}$, $\mathrm{Fe}^{3+}$ e $\mathrm{Mn}^{2+}$ e calculadas a capacidade de troca de cátions a pH 7 e a saturação por bases. $\mathrm{O}$ pH foi determinado em água. O carbono e o nitrogênio total do solo foram determinados pelo método de combustão a seco no analisador elementar CHNS/O Perkin-Elmer modelo 2400 Series II. O Al ${ }^{3+}, \mathrm{Ca}^{2+} \mathrm{e}$ $\mathrm{Mg}^{2+}$ foram extraídos em $\mathrm{KCl}$ a $1 \mathrm{~mol} \mathrm{~L}^{-1}$, sendo o primeiro determinado por titulação com $\mathrm{NaOH} 0,025 \mathrm{~mol} \mathrm{~L}^{-1}$ e os dois últimos por titulação de EDTA. A acidez potencial $\left(\mathrm{H}^{+}+\mathrm{Al}^{3+}\right)$ foi determinada por titulometria usando-se solução de acetato de cálcio $0,5 \mathrm{~mol} \mathrm{~L}^{-1}$ a $\mathrm{pH} 7$ para sua extração. $\mathrm{O}$ fósforo e o potássio foram extraídos com a solução de Mehlich $1(\mathrm{HCl}$ a $0,05 \mathrm{~mol} \mathrm{~L}^{-1}+\mathrm{H}_{2} \mathrm{SO}_{4}$ a $0,0125 \mathrm{~mol} \mathrm{~L}^{-1}$ ) e determinados em colorímetro e fotômetro de chama, respectivamente. Os micronutrientes foram determinados em espectrofotômetro de absorção atômica utilizando-se o extrator Mehlich 1. As análises laboratoriais foram realizadas de acordo com EMBRAPA (1997).

Os atributos biológicos avaliados foram carbono orgânico total do solo (COT), determinado pelo método de Walkley \& Black (EMBRAPA, 1997), carbono (CBM) e nitrogênio (NBM) da biomassa microbiana determinados, respectivamente, pelo método da fumigação-extração e pelo método de Kjeldhal, respiração basal do solo (RBS), determinada pela quantificação do $\mathrm{CO}_{2}$ liberado durante a incubação do solo em sistema fechado, quociente metabólico $\left(\mathrm{qCO}_{2}\right)$, obtido pela relação entre RBS e CBM, e microbiano (qmic), obtido pela relação entre CBM e COT, relação entre NBM e $\mathrm{N}$ total, atividade enzimática total do solo (AET) pelo método de hidrólise do diacetato de fluoresceína, atividades da $\beta$-glicosidase (ABG) e da fosfatase ácida (AFA) pelo método da determinação colorimétrica do p-nitrofenol, liberado pelas enzimas, quando o solo é incubado com os substratos específicos p-nitrofenil-beta-D-glicopironosídeo e p-nitrofenil-fosfato, respectivamente. Mais detalhes sobre a determinação desses atributos são apresentados em Ferreira et al. (2011).

Para cada atributo estudado e para a produtividade foram calculadas medidas estatísticas descritivas e se estabeleceram correlações entre eles. Foi realizada, também, análise de regressão múltipla para verificar quais os atributos do solo que mais influenciaram, de maneira conjunta, a produtividade do arroz. Para isto se verificou, inicialmente, a existência de colinearidade entre os atributos de solo eliminando-se aqueles que apresentaram correlações maiores que $85 \%$. A análise de regressão múltipla foi aplicada considerando os demais atributos do solo e o resíduo analisado com a finalidade de verificar se a distribuição era normal, por meio do gráfico "Q-Q plot", que compara o quantil amostral versus o quantil esperado sob normalidade e do teste de normalidade de Shapiro-Wilk. Os valores residuais padronizados e os valores observados foram plotados para verificar a ausência de autorregressão e a variância constante de erros; após esses procedimentos aplicou-se o método "stepwise" adotando-se, como critério, o AIC (Akaike Information Criterion). Para executar os procedimentos descritos anteriormente utilizou-se o programa estatístico R (R Development Core Team, 2011).

\section{Resultados e Discussão}

A densidade do solo apresentou valor médio (Tabela 1) abaixo da densidade considerada crítica para solos argilosos, que se situa entre 1,30 e 1,40 $\mathrm{Mg} \mathrm{m}^{-3}$ (Reichert et al., 2003). Já o valor máximo observado situou-se próximo ao limite superior. Esses limites correspondem aproximadamente à faixa de porosidade total de 0,47 a $0,51 \mathrm{~m}^{3} \mathrm{~m}^{-3}$. O valor mínimo deste atributo foi $0,47 \mathrm{~m}^{3} \mathrm{~m}^{-3}$ (Tabela 1). Beutler et al. (2004a), em um Latossolo Vermelho eutroférrico, textura argilosa, verificaram que a produtividade do arroz de terras altas foi reduzida de $34 \%$ quando a densidade do solo aumentou de 1,24 para 1,39 $\mathrm{Mg} \mathrm{m}^{-3}$ e a porosidade diminuiu de 0,48 para $0,44 \mathrm{~m}^{3} \mathrm{~m}^{-3}$.

A microporosidade variou entre 0,33 e $0,41 \mathrm{~m}^{3} \mathrm{~m}^{-3}$ (Tabela 1). Beutler et al. (2004a) observaram redução na produtividade do arroz com o aumento da microporosidade de 0,36 para 0,38 $\mathrm{m}^{3} \mathrm{~m}^{-3}$, em Latossolo Vermelho argiloso. A macroporosidade apresentou valor médio superior a $0,10 \mathrm{~m}^{3} \mathrm{~m}^{-3}$ (Tabela 1 ), considerado limite inferior da porosidade de aeração, abaixo do qual a difusão de oxigênio se torna limitante ao crescimento e desenvolvimento das raízes, embora o valor mínimo deste atributo tenha ficado abaixo deste limite.

O DMP e a porcentagem de agregados com diâmetro maior que $2 \mathrm{~mm}$ apresentaram valores médios de, respectivamente, $6,9 \mathrm{~mm}$ e $64,9 \%$ (Tabela 1), os quais podem ser considerados altos (Volk \& Cogo, 2008) e ser atribuídos ao não revolvimento do solo e ao carbono orgânico, o que melhora a agregação do solo. O valor máximo de RP (Tabela 1) não ultrapassou o limite de $2 \mathrm{MPa}$ que, comumente, tem sido associado como impeditivo para o crescimento das raízes; no entanto, Beutler et al. (2004b) verificaram que a compactação do solo a partir de um valor de RP de 1,82 MPa, medido na umidade do solo correspondente a $0,01 \mathrm{MPa}$, reduziu a produtividade do arroz de terras altas.

Andrade \& Stone (2009) estabeleceram, para solos de Cerrado, o limite de $\mathrm{S}<0,025$ para solos degradados fisicamente e $S \geq 0,045$ para solo com boa qualidade física. A média e a mediana relativas a este índice se situaram acima do limite superior (Tabela 1). O valor mínimo, entretanto, situouse entre esses dois limites sinalizando que em algumas situações a qualidade física do solo não estava adequada.

Os teores médios de $\mathrm{CeN}$ total foram iguais, respectivamente, a 25 e 1,9 $\mathrm{g} \mathrm{kg}^{-1}$ (Tabela 1). Em Latossolos do Cerrado sob semeadura direta, Siqueira Neto et al. (2009) encontraram o valor de $20 \mathrm{~g} \mathrm{~kg}^{-1}$ para o C total, em Rio Verde, GO, com a sucessão soja-milho ou sorgo, e Coser et al. (2007), no DF, verificaram teores de $\mathrm{N}$ total entre 0,8 e $1,3 \mathrm{~g} \mathrm{~kg}^{-1}$, no cultivo da cevada. Observa-se que os teores de $\mathrm{C}$ e $\mathrm{N}$ total encontrados neste trabalho são considerados comuns para solo de Cerrado sob cultivo.

Considerando as médias e as medianas (Tabela 1), o teor de alumínio foi classificado baixo, os valores de $\mathrm{pH}$ e de acidez 
Tabela 1. Medidas estatísticas descritivas dos atributos do solo estudado e da produtividade do arroz

\begin{tabular}{|c|c|c|c|c|c|c|}
\hline Atributos/produtividade & Média & Mediana & Máximo & Mínimo & Desvio-padrão & Variância \\
\hline Densidade do solo $\left(\mathrm{Mg} \mathrm{m}^{-3}\right)$ & 1,26 & 1,25 & 1,41 & 1,14 & 0,06 & 0,004 \\
\hline Porosidade total $\left(\mathrm{m}^{3} \mathrm{~m}^{-3}\right)$ & 0,53 & 0,53 & 0,57 & 0,47 & 0,02 & $<0,001$ \\
\hline Microporosidade $\left(\mathrm{m}^{3} \mathrm{~m}^{-3}\right)$ & 0,38 & 0,38 & 0,41 & 0,33 & 0,02 & $<0,001$ \\
\hline Macroporosidade $\left(\mathrm{m}^{3} \mathrm{~m}^{-3}\right)$ & 0,15 & 0,15 & 0,21 & 0,08 & 0,03 & 0,001 \\
\hline Agregados com diâmetro > 2 mm (\%) & 64,90 & 64,20 & 84,80 & 39,80 & 9,90 & 98,084 \\
\hline Diâmetro médio ponderado dos agregados $(\mathrm{mm})$ & 6,90 & 6,70 & 10,80 & 3,80 & 1,66 & 2,743 \\
\hline Resistência do solo à penetração (MPa) & 1,42 & 1,41 & 1,96 & 1,14 & 0,19 & 0,037 \\
\hline Índice S & 0,05 & 0,05 & 0,06 & 0,03 & 0,01 & $<0,001$ \\
\hline Carbono total $\left(\mathrm{g} \mathrm{kg}^{-1}\right)$ & 25,00 & 25,00 & 31,60 & 20,20 & 2,38 & 5,685 \\
\hline Nitrogênio total $\left(\mathrm{g} \mathrm{kg}^{-1}\right)$ & 1,90 & 1,90 & 2,40 & 1,40 & 0,27 & 0,074 \\
\hline pH em água & 5,54 & 5,55 & 6,10 & 4,82 & 0,24 & 0,060 \\
\hline Teor de cálcio trocável $\left(\mathrm{mmol}_{\mathrm{c}} \mathrm{dm}^{-3}\right)$ & 24,20 & 23,50 & 34,50 & 15,80 & 4,99 & 24,891 \\
\hline Teor de magnésio trocável $\left(\mathrm{mmol}_{\mathrm{c}} \mathrm{dm}^{-3}\right)$ & 10,10 & 9,50 & 14,50 & 6,20 & 2,45 & 5,986 \\
\hline Teor de alumínio trocável $\left(\mathrm{mmol}_{\mathrm{c}} \mathrm{dm}^{-3}\right)$ & 0,63 & 0,50 & 2,33 & 0,00 & 0,65 & 0,418 \\
\hline Teor de $\mathrm{H}+\mathrm{Al}\left(\mathrm{mmol}_{\mathrm{c}} \mathrm{dm}^{-3}\right)$ & 48,20 & 46,50 & 73,00 & 36,80 & 8,32 & 69,260 \\
\hline Teor de fósforo disponível (mg dm³) & 14,40 & 12,40 & 31,80 & 5,20 & 7,07 & 49,980 \\
\hline Teor de potássio disponível $\left(\mathrm{mg} \mathrm{dm}^{-3}\right)$ & 80,80 & 79,80 & 148,30 & 37,80 & 24,53 & 601,833 \\
\hline Teor de cobre disponível $\left(\mathrm{mg} \mathrm{dm}^{-3}\right)$ & 1,80 & 1,80 & 2,88 & 1,12 & 0,37 & 0,140 \\
\hline Teor de zinco disponível (mg dm-3) & 3,70 & 3,68 & 7,18 & 1,42 & 1,27 & 1,610 \\
\hline Teor de ferro disponível $\left(\mathrm{mg} \mathrm{dm}^{-3}\right)$ & 36,30 & 35,30 & 68,40 & 23,90 & 8,00 & 64,083 \\
\hline Teor de manganês disponível $\left(\mathrm{mg} \mathrm{dm}^{-3}\right)$ & 33,20 & 26,80 & 58,00 & 13,50 & 15,79 & 249,400 \\
\hline Capacidade de troca catiônica $\left(\mathrm{mmol}_{\mathrm{c}} \mathrm{dm}^{-3}\right)$ & 84,70 & 85,60 & 104,50 & 71,00 & 6,33 & 40,058 \\
\hline Saturação por bases (\%) & 43,10 & 42,60 & 58,00 & 29,00 & 7,91 & 62,620 \\
\hline Carbono orgânico total $\left(\mathrm{g} \mathrm{kg}^{1}\right)$ & 14,00 & 13,80 & 18,80 & 12,00 & 1,42 & 2,017 \\
\hline Carbono da biomassa microbiana- CBM (mg kg-1) & 202,30 & 182,20 & 404,40 & 113,20 & 74,34 & 5526,004 \\
\hline Nitrogênio da biomassa microbiana- NBM (mg g-1) & 29,80 & 29,20 & 53,40 & 14,20 & 10,34 & 106,811 \\
\hline Atividade enzimática total $\left(\mu \mathrm{g} \mathrm{FDA} \mathrm{g}{ }^{-1}\right.$ solo seco $\left.\mathrm{h}^{-1}\right)$ & 89,00 & 86,70 & 176,50 & 48,80 & 26,19 & 685,901 \\
\hline Atividade da $\beta$-glicosidase ( $\mu \mathrm{g} p$-nitrofenol $\mathrm{g}^{-1}$ solo seco $\mathrm{h}^{-1}$ ) & 63,80 & 62,70 & 98,40 & 32,40 & 12,74 & 162,416 \\
\hline Atividade da fosfatase ácida ( $\mu \mathrm{g}$ p-nitrofenol $\mathrm{g}^{-1}$ solo seco $\mathrm{h}^{-1}$ ) & 322,60 & 308,00 & 554,50 & 173,10 & 97,50 & 9506,311 \\
\hline Respiração basal do solo $\left(\mathrm{mg} \mathrm{C}^{-} \mathrm{CO}_{2} \mathrm{~kg}^{-1} \mathrm{~h}^{-1}\right)$ & 1,28 & 1,24 & 2,13 & 0,69 & 0,32 & 0,104 \\
\hline Quociente metabólico (mg C-CO $\left.\mathrm{kg}^{-1} \mathrm{CBM} \mathrm{h}^{-1}\right)$ & 7,03 & 7,04 & 12,07 & 2,99 & 2,24 & 5,009 \\
\hline Quociente microbiano (\%) & 1,43 & 1,35 & 2,82 & 0,76 & 0,46 & 0,210 \\
\hline Relação NBM:N total (\%) & 1,52 & 1,39 & 2,45 & 0,81 & 0,40 & 0,164 \\
\hline Produtividade $\left(\mathrm{kg} \mathrm{ha}^{-1}\right)$ & 1403,00 & 830,00 & 4558,00 & 103,00 & 1309,00 & 1713460,000 \\
\hline
\end{tabular}

potencial, médios, os teores dos demais nutrientes como adequados ou altos (Souza \& Lobato, 2004) e a CTC média (Freire, 2003). A saturação por bases apresentou média e mediana próximas de $43 \%$, valor que pode ser considerado adequado para a cultura do arroz (Fageria, 2001).

O teor de carbono orgânico total situou-se na faixa média de acordo com a classificação de Freire (2003). O CBM e o NBM apresentaram valores médios de, respectivamente, 202,3 e 29,8 $\mathrm{mg} \mathrm{kg}^{-1}$ (Tabela 1). Santos et al. (2007) obtiveram produtividades de arroz de terras altas ao redor de $3.000 \mathrm{~kg}$ $\mathrm{ha}^{-1}$ com manejos de solo que propiciaram teores de CBM entre 161 e $236 \mathrm{mg} \mathrm{kg}^{-1}$, valores compatíveis com os verificados no presente trabalho. Em solo cultivado com cevada, Coser et al. (2007) obtiveram teores de NBM variando de 11,4 a 38,4 mg kg-1, mesma ordem de valores deste trabalho.

Os valores médios das atividades da $\beta$-glicosidase e fosfatase ácida foram, respectivamente, 63,8 e 332,6 $\mu \mathrm{g}$ p-nitrofenol g ${ }^{-1}$ solo seco $\mathrm{h}^{-1}$ (Tabela 1), valores compatíveis, embora superiores, aos encontrados por Ferreira et al. (2011) para a mesma classe de solo, no florescimento do milho cultivado sob semeadura direta. A AET, contudo, apresentou valores inferiores aos observados por esses autores.

Os valores médios para a $\mathrm{RBS}$ e o $\mathrm{qCO}_{2}$ foram, respectivamente, $1,28 \mathrm{mg} \mathrm{C}-\mathrm{CO}_{2} \mathrm{~kg}^{-1} \mathrm{~h}^{-1}$ e 7,03 $\mathrm{mg} \mathrm{C}^{2} \mathrm{CO}_{2} \mathrm{~kg}^{-1} \mathrm{CBM} \mathrm{h}^{-1}$, valores superiores aos observados por Ferreira et al. (2011), indicando ambientes com maior grau de distúrbio ou estresse.

Em condições normais, o quociente microbiano varia de 1 a $4 \%$ e valores inferiores a $1 \%$ podem ser atribuídos a algum fator limitante à atividade da biomassa microbiana (Jakelaitis et al., 2008). A média e a mediana foram superiores a $1 \%$; entretanto, o valor mínimo foi inferior a este valor (Tabela 1), indicando que em algumas situações a atividade dos micro-organismos pode ter sido prejudicada o que também pode ser observado com a relação NBM:N total, que apresentou valores entre 0,81 e $2,45 \%$, sendo considerados adequados os valores acima de $1 \%$ (Coser et al., 2007).

A produtividade média foi de $1.403 \mathrm{~kg} \mathrm{ha}^{-1}$ (Tabela 1), abaixo da média de Goiás no ano de 2011, que foi de $2.162 \mathrm{~kg}$ ha $^{-1}$ (EMBRAPA, 2014), devido à inclusão de áreas de segundo $\left(628 \mathrm{~kg} \mathrm{ha}^{-1}\right)$ e terceiro anos $\left(712 \mathrm{~kg} \mathrm{ha}^{-1}\right)$ de cultivo de arroz. Quando o arroz de terras altas é cultivado por dois ou mais anos na mesma área, ocorre queda acentuada da sua produtividade em relação ao primeiro cultivo (2.266 $\left.\mathrm{kg} \mathrm{ha}^{-1}\right)$, o que tem sido atribuído a efeitos alelopáticos (Fageria \& Baligar, 2003).

A produtividade foi afetada negativamente pela microporosidade e pelo $\mathrm{qCO}_{2}$ e apresentou correlação significativa e positiva com $\mathrm{N}$ total, $\mathrm{Cu}, \mathrm{Fe}, \mathrm{Mn}, \mathrm{CBM}, \mathrm{NBM}$, AET, AFA, qmic e relação NBM:N total (Tabela 2).

Como não há revolvimento do solo na semeadura direta, as pressões ocasionadas pelo tráfego de máquinas e a acomodação natural das partículas, elevam o estado de compactação do solo reduzindo o tamanho dos poros. Beutler et al. (2004a) também observaram correlação negativa entre a microporosidade e a produtividade do arroz. Com o aumento da microporosidade diminui o alongamento radicular visto que as raízes do arroz não conseguem reduzir seu diâmetro para penetrar nos 
Tabela 2. Correlação de Pearson entre os atributos do solo e a produtividade do arroz sob diferentes manejos do solo e plantas de cobertura $(n=39)$

\begin{tabular}{|c|c|c|c|c|c|}
\hline \multirow{2}{*}{ Atributos } & \multicolumn{2}{|c|}{ Correlação } & \multirow{2}{*}{ Atributos } & \multicolumn{2}{|c|}{ Correlação } \\
\hline & $r$ & $\mathbf{P}^{\#}$ & & $r$ & $\mathbf{P}^{\#}$ \\
\hline Densidade do solo ( $\left.\mathrm{Mg} \mathrm{m}^{3}\right)$ & 0,14 & 0,392 & Teor de cobre disponível $\left(\mathrm{mg} \mathrm{dm}^{-3}\right)$ & 0,58 & $<0,001$ \\
\hline Porosidade total $\left(\mathrm{m}^{3} \mathrm{~m}^{-3}\right)$ & $-0,14$ & 0,392 & Teor de zinco disponível (mg dm³) & $-0,16$ & 0,313 \\
\hline Macroporosidade $\left(\mathrm{m}^{3} \mathrm{~m}^{-3}\right)$ & 0,13 & 0,442 & Teor de manganês disponível (mg dm-3) & 0,60 & $<0,001$ \\
\hline Agregados com diâmetro > 2 mm (\%) & 0,17 & 0,302 & Capacidade de troca catiônica $\left(\mathrm{mmot} \mathrm{dm}^{-3}\right)$ & 0,24 & 0,138 \\
\hline Diâmetro médio ponderado dos agregados (mm) & 0,07 & 0,683 & Saturação por bases (\%) & 0,04 & 0,784 \\
\hline Resistência do solo à penetração (MPa) & $-0,10$ & 0,546 & Carbono orgânico total $\left(\mathrm{g} \mathrm{kg}^{1}\right)$ & 0,31 & 0,052 \\
\hline Índice S & $-0,26$ & 0,115 & Carbono da biomassa microbiana- CBM (mg kg $\left.{ }^{-1}\right)$ & 0,51 & $<0,001$ \\
\hline Carbono total $\left(\mathrm{g} \mathrm{kg}^{-1}\right)$ & 0,17 & 0,304 & Nitrogênio da biomassa microbiana- NBM (mg kg-1) & 0,64 & $<0,001$ \\
\hline Nitrogênio total $\left(\mathrm{g} \mathrm{kg}^{-1}\right)$ & 0,37 & 0,020 & Atividade enzimática total ( $\mu \mathrm{g} \mathrm{FDA} \mathrm{g}{ }^{-1}$ solo seco $\left.\mathrm{h}^{-1}\right)$ & 0,43 & 0,006 \\
\hline pH em água & $-0,07$ & 0,656 & Atividade da $\beta$-glicosidase ( $\mu \mathrm{g} p$-nitrofenol $\mathrm{g}^{-1}$ solo seco $\mathrm{h}^{-1}$ ) & 0,22 & 0,176 \\
\hline Teor de cálcio trocável $\left(\mathrm{mmol}_{\mathrm{c}} \mathrm{dm}^{-3}\right)$ & 0,16 & 0,340 & Atividade da fosfatase ácida ( $\mu \mathrm{g} \mathrm{p}$-nitrofenol $\mathrm{g}^{-1}$ solo seco $\mathrm{h}^{-1}$ ) & 0,63 & $<0,001$ \\
\hline Teor de magnésio trocável $\left(\mathrm{mmol}_{\mathrm{c}} \mathrm{dm}^{-3}\right)$ & 0,08 & 0,627 & Respiração basal do solo $\left(\mathrm{mg} \mathrm{C}-\mathrm{CO}_{2} \mathrm{~kg}^{-1} \mathrm{~h}^{-1}\right)$ & 0,11 & 0,492 \\
\hline Teor de alumínio trocável $\left(\mathrm{mmol}_{\mathrm{c}} \mathrm{dm}^{-3}\right)$ & 0,07 & 0,648 & Quociente metabólico $\left(\mathrm{mg} \mathrm{C}-\mathrm{CO}_{2} \mathrm{~kg}^{-1} \mathrm{CBM} \mathrm{h}^{-1}\right)$ & $-0,39$ & 0,015 \\
\hline Teor de $\mathrm{H}+\mathrm{Al}\left(\mathrm{mmol}_{\mathrm{c}} \mathrm{dm}^{-3}\right)$ & 0,08 & 0,627 & Quociente microbiano (\%) & 0,47 & 0,002 \\
\hline Teor de fósforo disponível (mg dm³) & $-0,16$ & 0,341 & Relação NBM:N total (\%) & 0,60 & $<0,001$ \\
\hline Teor de potássio disponível $\left(\mathrm{mg} \mathrm{dm}^{-3}\right)$ & $-0,19$ & 0,245 & & & \\
\hline
\end{tabular}

\# nível de significancia

microporos, menores que suas extremidades (Medeiros et al., 2005).

A correlação negativa com $\mathrm{qCO}_{2}$ indica que, em algumas situações, ocorreu condição de estresse ou distúrbio na microbiota do solo afetando a produtividade do arroz. Zilli et al. (2008) constataram alterações na comunidade microbiana do solo com o uso do herbicida glifosato. Essas alterações, embora muitas vezes sejam consideradas temporárias, podem representar ruptura do equilíbrio biodinâmico no solo interferindo diretamente na decomposição/mineralização da matéria orgânica, ciclagem de nutrientes e supressão de doenças, entre outros. Ao longo do tempo essas alterações podem representar a perda da qualidade do solo. Além disto, é possível que o acúmulo de exsudatos liberados pelas plantas de arroz com os cultivos sucessivos também altere a comunidade microbiana (Fageria \& Baligar, 2003). Outra provável causa de perturbação da microbiota é a redução da porosidade de aeração com o aumento da microporosidade em detrimento da macroporosidade uma vez que a correlação entre $\mathrm{qCO}_{2}$ e a microporosidade foi significativa e positiva $(\mathrm{r}=0,52 ; \mathrm{p}<0,01)$.

A correlação positiva com o teor de $\mathrm{N}$ total do solo é devida, provavelmente, ao fato de as plantas de arroz na fase inicial de crescimento apresentarem baixa capacidade de redução do nitrato o qual, pelas condições favoráveis ao processo de nitrificação, seria a forma de $\mathrm{N}$ mineral predominante na camada superficial do solo (Soares, 2004). $\mathrm{O}$ não aproveitamento do nitrato seria em razão da baixa atividade da enzima redutase do nitrato nesta fase. Assim, $\mathrm{o}$ arroz depende de fornecimento constante de $\mathrm{N}$ amoniacal na fase inicial, o que pode ser obtido pela decomposição da matéria orgânica do solo. Como o $\mathrm{N}$ do solo se encontra quase totalmente complexado na forma orgânica (98\%), dependendo da biomassa microbiana do solo para sua transformação e consequente absorção pelas plantas (Coser et al., 2007), quanto maior seu teor no solo maior, provavelmente, o fornecimento de $\mathrm{N}$ amoniacal para o arroz.

Observou-se correlação positiva $(\mathrm{r}=0,70$; $\mathrm{p}<0,01)$ entre $\mathrm{N}$ total e NBM. Pequenas mudanças na estrutura da biomassa microbiana podem resultar em grandes mudanças no NBM e, portanto, no teor de $\mathrm{N}$ total (Coser et al., 2007). Assim, é provável que o aumento da microporosidade tenha afetado a comunidade microbiana com reflexos no NBM, de vez que a correlação entre este atributo e a microporosidade, foi negativa $(\mathrm{r}=-0,50 ; \mathrm{p}<0,01)$. Por outro lado, o uso do glifosato e o acúmulo de exsudatos liberados pelas plantas de arroz pelos cultivos sucessivos também podem ter afetado o acúmulo de $\mathrm{N}$ pela biomassa microbiana. Isto refletiu na produtividade do arroz visto que ela apresentou correlação positiva com o NBM. A correlação positiva entre este atributo e a produtividade também foi observada por Yusuf et al. (2009), para milho.

Em razão do não revolvimento do solo na semeadura direta, a decomposição da matéria orgânica do solo e a consequente liberação de $\mathrm{N}$ amoniacal, são lentas. Se este pouco $\mathrm{N}$ amoniacal produzido na mineralização não for absorvido pela planta será imobilizado pelos micro-organismos ou rapidamente nitrificado a nitrato, haja vista que na superfície do solo o meio é rico em oxigênio. Assim, no sistema de semeadura direta o arroz sofre intensa carência de $\mathrm{N}$ amoniacal em razão da já comentada baixa atividade da redutase do nitrato. Referida deficiência afeta fortemente o desenvolvimento radicular, o perfilhamento e o desenvolvimento inicial do arroz (Soares, 2004).

As correlações positivas da produtividade com os teores de $\mathrm{Cu}, \mathrm{Fe}$ e $\mathrm{Mn}$ podem ser devidas ao fato do glifosato afetar a absorção desses micronutrientes pela formação de compostos insolúveis (Coutinho \& Mazo, 2005); assim, quanto maior seu teor no solo maior também a disponibilidade para absorção pelo arroz. Em algumas parcelas as plantas de arroz apresentavam sintomas visuais de deficiência de $\mathrm{Cu}$. Ademais, Johal \& Huber (2009) constataram que o glifosato causou decréscimo na população de organismos redutores e aumento na de oxidantes de Mn na rizosfera. A maior população de organismos oxidantes favoreceu a transformação do $\mathrm{Mn}^{2+}$, forma ativa, absorvível pelas plantas, em $\mathrm{Mn}^{4+}$, forma inativa, não absorvível pelas plantas.

Além disso, a microporosidade apresentou correlação negativa com os teores de $\mathrm{Cu}(\mathrm{r}=-0,62 ; \mathrm{p}<0,01), \mathrm{Fe}(\mathrm{r}=-0,59$; $\mathrm{p}<0,01)$ e $\mathrm{Mn}(\mathrm{r}=-0,57 ; \mathrm{p}<0,01)$. Como uma das principais fontes desses micronutrientes é a matéria orgânica, com o incremento da microporosidade a quantidade e a atividade 
dos micro-organismos que fazem sua ciclagem podem ter sido afetadas, uma vez que tanto o CBM como a AET apresentaram correlação negativa com a microporosidade $(r=-0,54 ; \mathrm{p}<0,01$ e $r=-0,58 ; p<0,01$, respectivamente). Ogunremi et al. (1986) verificaram que altas produtividades de arroz de terras altas estavam associadas à maior absorção de Cu e Mn nos estádios de máximo perfilhamento e floração.

A correlação da produtividade com o CBM pode ser explicada pelo fato de que maior quantidade de CBM reflete a presença de maior quantidade de matéria orgânica ativa no solo, capaz de manter elevada taxa de decomposição de restos vegetais e, portanto, de reciclar mais nutrientes. Realmente, a $\mathrm{CBM}$ apresentou correlação positiva com os teores de $\mathrm{Cu}(\mathrm{r}=$ $0,63 ; \mathrm{p}<0,01), \mathrm{Fe}(\mathrm{r}=0,76 ; \mathrm{p}<0,01)$ e $\mathrm{Mn}(\mathrm{r}=0,55 ; \mathrm{p}<0,01)$. A correlação positiva entre CBM e produtividade também foi observada por Yusuf et al. (2009), para milho e por Lopes et al. (2013), para soja e milho.

A AET é utilizada como indicador geral da atividade hidrolítica do solo, medida pelas atividades de proteases, lipases e esterases, capazes de clivar compostos fluorogênicos (Taylor et al., 2002). Quanto maior seu valor maior é o efeito no ciclo de energia do sistema solo-planta e de nutrientes no solo sinalizando a importância da decomposição de materiais orgânicos para a produtividade do arroz. A AET também apresentou correlação positiva com os teores de $\mathrm{Cu}(\mathrm{r}=0,56$; $\mathrm{p}<0,01), \mathrm{Fe}(\mathrm{r}=0,75 ; \mathrm{p}<0,01)$ e $\mathrm{Mn}(\mathrm{r}=0,57 ; \mathrm{p}<0,01)$.

Os teores de $\mathrm{P}$ no solo variaram de médios a altos; assim, é possível que em algumas situações a atuação mais efetiva da AFA na ciclagem do P orgânico tenha contribuído de forma relevante para a nutrição fosfatada do arroz uma vez que ela apresentou correlação positiva com a produtividade do arroz $(\mathrm{r}=0,63 ; \mathrm{p}<0,01)$. A AFA também apresentou correlação positiva com o CBM ( $\mathrm{r}=0,68$; $\mathrm{p}<0,01)$, o que é coerente, visto que as fosfatases se originam predominantemente da biomassa microbiana.

A correlação positiva da produtividade com qmic mostra a importância da microbiota do solo para o arroz. Maiores valores de qmic indicam condições apropriadas para o desenvolvimento microbiano as quais podem decorrer da adição de matéria orgânica de boa qualidade ou eliminação de algum fator limitante (Jakelaitis et al., 2008). Da mesma forma, a correlação da produtividade com a relação NBM:N total sinaliza a importância da qualidade da matéria orgânica para o arroz pois quanto maior esta relação melhor será esta qualidade (Coser et al., 2007).

Considerando todos os atributos do solo, os que melhor explicaram de maneira conjunta a produtividade do arroz (PROD) foram os teores de $\mathrm{Cu}, \mathrm{Fe}$ e $\mathrm{NBM}$ e a AFA, sendo ajustada a seguinte equação de regressão linear múltipla, com $\mathrm{R}^{2}$ de $0,58^{\star *}$ :

$$
\begin{aligned}
\text { PROD } & =-2337,8 * *+2663,9 \mathrm{Cu} * *-115,2 \mathrm{Fe}^{* *}+ \\
& +26,6 \mathrm{NBM} *+7,2 \mathrm{AFA} * *
\end{aligned}
$$

A produtividade das culturas pode ser influenciada por vários fatores que não estão relacionados com a qualidade do solo, tais como clima, genótipo e ocorrência de pragas (Lopes et al., 2013). Assim, a obtenção de um conjunto de atributos do solo que explique $58 \%$ da produtividade pode ser considerada altamente satisfatória e atribuída à escolha de áreas e locais com alta variabilidade nos atributos e na produtividade.

A presença da AFA na equação realça a importância do fósforo orgânico e sinaliza que em algumas situações o fósforo fornecido via fertilizante e presente na solução do solo pode não estar sendo suficiente para a nutrição do arroz. Lopes et al. (2013), verificaram, considerando experimentos sobre manejo do $\mathrm{P}$, correlação positiva entre a AFA e a produtividade acumulada relativa de soja e milho.

O NBM reflete o papel da biomassa microbiana na ciclagem de nutrientes no solo especialmente do nitrogênio. Tal atributo é altamente afetado pelo tipo do substrato, sendo favorecido pelas leguminosas e pode representar mais de 0,05 do total de $\mathrm{N}$ no solo influenciando a disponibilidade de nutrientes e a produtividade dos agroecossistemas (Yusuf et al., 2009). Neste trabalho o NBM variou entre 0,80 e $2,45 \%$ do $\mathrm{N}$ total (Tabela 1). Assim, apesar de alguns antecedentes culturais impactarem mais positivamente este atributo, há necessidade de mais estudos no sentido de se estabelecer as rotações mais adequadas para o arroz de terras altas uma vez que o NBM é um indicador muito sensível da qualidade de solos com teores de carbono orgânico menores que $25 \mathrm{~g} \mathrm{~kg}^{-1}$ (Yusuf et al., 2009), como grande parte dos solos de Cerrado.

$\mathrm{O} \mathrm{Cu}$ foi, provavelmente, consequência da deficiência desse nutriente apresentada por plantas de arroz talvez em razão da sua indisponibilidade pela aplicação de glifosato ou problemas na sua ciclagem por alterações na comunidade microbiana, como já discutido. A presença do Fe com sinal negativo provavelmente é para manter o equilíbrio com o $\mathrm{Cu}$ de vez que esses nutrientes apresentaram alta correlação positiva $(\mathrm{r}=0,84 ; \mathrm{p}<0,01)$.

Desta maneira, manejos que aportem matéria orgânica de boa qualidade e favoreçam a quantidade e a atividade dos micro-organismos do solo resultarão, sem dúvida, em maior produtividade do arroz. A presença de maior quantidade de matéria orgânica ativa no solo, capaz de manter elevada taxa de decomposição de restos vegetais e, portanto, de reciclar mais nutrientes, refletirá em sua maior disponibilidade para o arroz. De acordo com Lopes et al. (2013), solos altamente produtivos apresentam altos níveis de biomassa e atividade microbiana os quais resultam, com o incremento do teor de matéria orgânica do solo, em solos de alta qualidade.

\section{Conclusões}

1. O N total, cobre, ferro, manganês, CBM, NBM, AET, AFA, qmic e a relação NBM:N total, se correlacionaram positivamente com a produtividade do arroz.

2. A microporosidade e o quociente metabólico indicam alguma condição de estresse no solo e se correlacionaram negativamente com a produtividade do arroz.

3. Os teores de cobre, ferro e NBM e a AFA foram os atributos do solo que, conjuntamente, apresentaram maior correlação com a produtividade do arroz.

\section{Literatura Citada}

Andrade, R. da S.; Stone, L. F. Índice S como indicador da qualidade física de solos do cerrado brasileiro. Revista Brasileira de Engenharia Agrícola e Ambiental, v.13, p.382-388, 2009. http:// dx.doi.org/10.1590/S1415-43662009000400003 
Beutler, A. N.; Centurion, J. F.; Roque, C. G. Relação entre alguns atributos físicos e a produção de grãos de soja e arroz de sequeiro em latossolos. Ciência Rural, v.34, p.365-371, 2004a. http://dx.doi. org/10.1590/S0103-84782004000200005

Beutler, A. N.; Centurion, J. F.; Silva, A. P. da; Roque, C. G.; Ferraz, M. V. Compactação do solo e intervalo hídrico ótimo na produtividade do arroz de sequeiro. Pesquisa Agropecuária Brasileira, v.39, p.575-580, 2004b. http://dx.doi.org/10.1590/ S0100-204X2004000600009

Coser, T. R.; Ramos, M. L. G.; Amabile, R. F.; Ribeiro Júnior, W. Q. Nitrogênio da biomassa microbiana em solo de Cerrado com aplicação de fertilizante nitrogenado. Pesquisa Agropecuária Brasileira, v.42, p.399-406, 2007. http://dx.doi.org/10.1590/S0100204X2007000300014

Coutinho, C. F. B.; Mazo, L. H. Complexos metálicos com o herbicida glifosato: revisão. Química Nova, v.28, p.1038-1045, 2005. http:// dx.doi.org/10.1590/S0100-40422005000600019

Dexter, A. R. Soil physical quality. Part 1 . Theory, effects of soil texture, density, and organic matter, and effects on root growth. Geoderma, v.120, p.201-214, 2004. http://dx.doi.org/10.1016/j. geoderma.2003.09.004

EMBRAPA - Empresa Brasileira de Pesquisa Agropecuária. Centro Nacional de Pesquisa de Solos. Manual de métodos de análise de solos. 2.ed. Rio de Janeiro: Embrapa CNPS, 1997. 212p. Documentos, 1.

EMBRAPA - Empresa Brasileira de Pesquisa Agropecuária. Socioeconomia. <http://www.cnpaf.embrapa.br/socioeconomia/ index.htm>. 10 Jan. 2014.

Fageria, N. K. Resposta de arroz de terras altas, feijão, milho e soja à saturação por base em solo de cerrado. Revista Brasileira de Engenharia Agrícola e Ambiental, v.5, p.416-424, 2001. http:// dx.doi.org/10.1590/S1415-43662001000300009

Fageria, N. K.; Baligar, V. C. Upland rice and allelopathy. Communications in Soil Science and Plant Analysis, v.34, p.1311-1329, 2003. http://dx.doi.org/10.1081/CSS-120020447

Ferreira, E. P. B.; Wendland, A.; Didonet, A. D. Microbial biomass and enzyme activity of a Cerrado Oxisol under agroecological production system. Bragantia, v.70, p.899-907, 2011. http://dx.doi. org/10.1590/S0006-87052011000400024

Freire, F. M. Interpretação de resultados de análise de solo. Sete Lagoas: Embrapa Milho e Sorgo, 2003. 4p. Comunicado técnico, 82

Jakelaitis, A.; Silva, A. A. da; Santos, J. B. dos; Vivian, R. Qualidade da camada superficial de solo sob mata, pastagens e áreas cultivadas. Pesquisa Agropecuária Tropical, v.38, p.118-127, 2008.

Johal, G. S.; Huber, D. M. Glyphosate effects on diseases of plants. European Journal of Agronomy, v.31, p.144-152, 2009. http:// dx.doi.org/10.1016/j.eja.2009.04.004

Lopes, A. A. de C.; Sousa, D. M. G. de; Chaer, G. M.; Reis Junior, F. B. dos; Goedert, W. J.; Mendes, I. de C. Interpretation of microbial soil indicators as a function of crop yield and organic carbon. Soil Science Society of America Journal, v.77, p.461-472, 2013. http:// dx.doi.org/10.2136/sssaj2012.0191

Medeiros, R. D. de; Soares, A. A.; Guimarães, R. M. Compactação do solo e manejo da água. I: Efeitos sobre a absorção de N, P, K, massa seca de raízes e parte aérea de plantas de arroz. Ciência e Agrotecnologia, v.29, p.940-947, 2005. http://dx.doi.org/10.1590/ S1413-70542005000500004
Mendes, F. G.; Melloni, E. G. P.; Melloni, R. Aplicação de atributos físicos do solo no estudo da qualidade de áreas impactadas, em Itajubá/MG. Cerne, v.12, p.211-220, 2006.

Ogunremi, L. T.; Lal, R.; Babalola, O. Effects of tillage and seeding methods on soil physical properties and yield of upland rice for an Ultisol in southeast Nigeria. Soil \& Tillage Research, v.6, p.305-324, 1986. http://dx.doi.org/10.1016/0167-1987(86)90030-9

R Development Core Team. R: A language and environment for statistical computing. Vienna: R foundation for statistical computing, 2011. http://www.R-project.org. 25 Jan. 2011.

Reichert, J. M.; Reinert, D. J.; Braida, J. A. Qualidade dos solos e sustentabilidade de sistemas agrícolas. Ciência \& Ambiente, v.27, p.29-48, 2003.

Reis, M. de S.; Soares, A. A.; Cornélio, V. M. de O.; Soares, P. C.; Guedes, J. M.; Costa Júnior, G. T. Comportamento de genótipos de arroz de terras altas sob sistemas de plantio direto e convencional. Pesquisa Agropecuária Tropical, v.37, p.227232, 2007.

Santos, T. E. B. dos; Nakayama, F. T.; Arf, O.; Cassiolato, A. M. R. Variáveis microbiológicas e produtividade do arroz sob diferentes manejos do solo e água. Acta Scientiarum. Agronomy, v.29, p.355366, 2007. http://dx.doi.org/10.4025/actasciagron.v29i3.281

Silva, S. C. da; Heinemann, A. B.; Paz, R. L. F.; Amorim, A. de O. Informações meteorológicas para pesquisa e planejamento agrícola, referentes ao ano de 2009, do município de Santo Antônio de Goiás, GO. Santo Antônio de Goiás: Embrapa Arroz e Feijão, 2010. 32p. Documentos, 256.

Siqueira Neto, M.; Piccolo, M. de C.; Scopel, E.; Costa Junior, C. da; Cerri, C. C.; Bernoux, M. Carbono total e atributos químicos com diferentes usos do solo no Cerrado. Acta Scientiarum. Agronomy, v.31, p.709-717, 2009.

Soares, A. A. Desvendando o segredo do insucesso do plantio direto do arroz de terras altas. Informe Agropecuário, v.25, p.58-66, 2004.

Souza, D. M. G.; Lobato, E. (ed.). Cerrado: Correção do solo e adubação. 2.ed. Brasília: Embrapa Informação Tecnológica, 2004. 416p.

Taylor, J. P.; Wilson, B.; Mills, M. S.; Burns, R. G. Comparison of microbial numbers and enzymatic activities in surface soils and sub soils using various techniques. Soil Biology and Biochemistry, v.34, p.387-401, 2002. http://dx.doi.org/10.1016/ S0038-0717(01)00199-7

Volk, L. B. da S.; Cogo, N. P. Inter-relação biomassa vegetal subterrânea-estabilidade de agregados-erosão hídrica em solo submetido a diferentes formas de manejo. Revista Brasileira de Ciência do Solo, v.32, p.1713-1722, 2008. http://dx.doi. org/10.1590/S0100-06832008000400036

Yusuf, A. A.; Abaidoo, R. C.; Iwuafor, E. N.; Olufajo, O. O.; Sanginga, $\mathrm{N}$. Rotation effects of grain legumes and fallow on maize yield, microbial biomass and chemical properties of an Alfisol in the Nigerian savanna. Agriculture, Ecosystems \& Environment, v.129, p.325-331, 2009. http://dx.doi.org/10.1016/j.agee.2008.10.007

Zilli, J. E.; Botelho, G. R.; Neves, M. C. P.; Rumjanek, N. G. Efeito de glyphosate e imazaquin na comunidade bacteriana do rizoplano de soja (Glycine max (L.) Merrill) e em características microbiológicas do solo. Revista Brasileira de Ciência do Solo, v.32, p.633-642, 2008. http://dx.doi.org/10.1590/S010006832008000200018 